\title{
Disulfiram and Copper gluconate in cancer chemotherapy; a review of the literature
}

\section{Georgewill Udeme Owunari, Siminialayi Iyeopu Minakiri}

Department of Pharmacology, Faculty of Basic Medical Sciences, College of Health Sciences, University of Port Harcourt, Port Harcourt, Rivers State, Nigeria

\section{Email address:}

udgeorgewill@yahoo.com (U.O. Georgewill)

\section{To cite this article:}

Georgewill Udeme Owunari, Siminialayi Iyeopu Minakiri. Disulfiram and Copper Gluconate in Cancer Chemotherapy; a Review of the Literature. Cancer Research Journal. Vol. 2, No. 5, 2014, pp. 88-92. doi: 10.11648/j.crj.20140205.12

\begin{abstract}
Repurposing non- cancer related drugs with possible antitumoral activities is a promising strategy for identifying prospective new anticancer drugs in a cost efficient and time saving way. Repurposing disulfiram has recently become of interest because of its pre-clinically described anticancer effects against various human cancers, which include breast, cervical, colorectal, lung, melanoma, prostate as well as myeloma and leukaemia. Epidemiological studies reveal a trend to reduced cancer risks in cancer patients using disulfiram for chronic alcoholism treatment while already reported literature point to the efficacy of disulfiram on cancer cell lines. Disulfiram has been shown to be effective either as a stand alone or in combination with other drugs against metastatic liver cancer, lung cancer, prostate cancer, glioblastoma and melanoma. Preclinical studies indicate that disulfiram when combined with copper ions acts as a proteasome inhibitor, to induce oxidative stress, reduce NFKB (Nuclear factor kappa Binding) activity and enhance the sensitivity of cancer cells to chemotherapeutic agents. This study analyzed existing literature and found that disulfiram in combination with copper gluconate is a promising therapeutic agent for use in cancer chemotherapy.
\end{abstract}

Keywords: Cancer, Disulfiram, Copper gluconate

\section{Introduction}

Cancer, a disease of uncontrollable cell division, invasion and metastasis, is an emerging public health problem in Africa. The International Agency for Research on Cancer (IARC), has estimated that approximately 715,000 new cancer cases and 542,000 cancer deaths occurred in 2008 in Africa[1]. The IARC further projects that these numbers are likely to double (1.28 million new cancer cases and 970,000 cancer deaths) by 2030 with a potential to even be higher as a result of ageing and growth of the population, adoption of behaviors and lifestyles associated with economic development, such as smoking, unhealthy diet, and physical inactivity. [1]

Cancer continues to receive low public health priority in Africa, despite the growing burden as a result of limited resources and other pressing public health problems, including communicable diseases such as acquired immune deficiency syndrome (AIDS)/human immunodeficiency virus (HIV) infection, malaria, tuberculosis and more recently the Ebola viral disease. It could also be attributed to a lack of awareness about the magnitude of the current and future cancer burden among policy makers, the general public, and international private or public health agencies [2].

Cancer occurrence in Africa varies significantly from that in economically developed regions. Indices such as type of major cancer, stage at diagnosis, survival, incidence and mortality rates account for this. This is due to differences in exposures to major risk factors, detection practices (availability of diagnostic and screening services), awareness of early signs and symptoms, and availability of treatment.

Cancer of the cervix, liver, urinary bladder and Kaposi sarcoma which are cancers related to infectious agents are among the dominant types of the disease in Africa [2]. In 2008 , cervical cancer accounted for $21 \%$ of the total newly diagnosed cancers in females and liver cancer for $11 \%$ of the total cancer cases in males.

Due to the lack of screening and early detection services, limited awareness of early signs and symptoms among public and health care providers as well as the social stigma associated with the diagnosis of cancer and hence late stage presentation of the disease, a majority of cancers in Africa 
are diagnosed at an advanced stage of the disease.

WHO estimates that cancer accounts for 13 percent of all deaths registered globally with 70 percent of that figure in middle and low income countries. The 2008 WHO Report estimated that about 10,000 cancer deaths and 250,000 new cases are recorded yearly in Nigeria [2]. In addition, only 17 percent of African countries are said to have sufficiently funded cancer control programs, while less than half of all countries in the world have functional plans to prevent the disease and provide treatment and care to the patients [2]. Furthermore, the shortage of functional cancer control plans is especially alarming in developing countries, which already account for more than two-thirds of the new cancer cases and deaths each year.

In Nigeria, the public still see cancer as a disease of the rich, the aged and the developed world. Many sufferers of the disease in the country still regard cancer as a death sentence having accepted the illness as their fate. Cancer is more than a health issue with far-reaching social and economic implications. It is a global epidemic that affects all ages as it does not discriminate, with low and middle income countries bearing the larger burden of the disease. [3]

In Nigeria, breast cancer, cervical cancer and prostate cancer are most prevalent amongst women and men respectively [2]. Added to this, is the burden cancer imposes on the Niger Delta region of Nigeria where this study is sited. More and more researchers attest to the fact that individuals in this region are at increasing risk of developing cancers as a result of oil exploration activities [3]. A research study on the analysis of the occurrence of cancers in the Niger Delta between 1997 and 2000 showed that the communities most affected were those in Bayelsa state, Etche, Ogoni, Port Harcourt and to a lesser extent the Kalabari, Okrika and Opobo tribes in Rivers state. The researchers go on to conclude that the incidence of cancer in these communities correlated with the polluting activities of oil companies in the region [4]. Other Studies affirm that Nigerians are at increased risk of developing different types of cancer due to exposure to crude oil pollutants. These studies postulate that more than 25 per cent of Nigerians are at an increased risk of developing cancer due to exposure to toxic chemicals from crude oil pollution, polynuclear aromatic hydrocarbons (PAHs). It is also suggested that PAHs can be genotoxic; that is, the damage caused can be inherited [3]. Therefore new, cheaper alternative drug treatment if available would help reduce the cancer burden.

\section{Disulfiram}

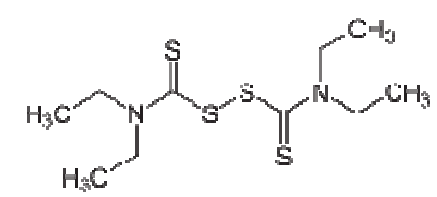

Fig 1. Chemical structure of Disulfiram (http://images.ddccdn.com/img/mol/DB00822.mol.t.jpg)
Disulfiram is a drug discovered in the 1920s and used for the treatment of chronic alcoholism by producing an acute sensitivity to alcohol [5]. It inhibits the enzyme acetaldehyde dehydrogenase, which breaks down alcohol, thus causing an unpleasant reaction when alcohol is consumed. Trade names for disulfiram in different countries are, Antabuse and Antabus [5].

Disulfiram, used for several decades in the treatment of alcoholism, now shows promise as an anticancer drug and radio sensitizer. Disulfiram-induced cytotoxicity has been reported to be mediated by oxidative stress [6-7], and this may be enhanced by the presence of copper [6]. Copper binding drugs inhibit proteasome activity [8] and generate reactive oxygen species (ROS) [9].

Disulfiram chelates copper, and it has been suggested that the disulfiram- copper complex is the toxic form of the drug [10]. Many tumours contain elevated levels of copper which render them selectively susceptible to disulfiram induced toxicity [8]. Researchers have observed that in the presence of copper, disulfiram exhibits cytotoxic effects on a number of cancer cell lines. It is postulated that disulfiram, chemically a bis-N, N-diethyldithiocarbamate forms a carbamato complex with $\mathrm{Cu}^{2+}$ ions in situ which inhibits the proteasome activity, instigating apoptosis and eventual cell death [10]. Disulfiram and a copper donor like copper gluconate or copper glycinate is under experimentation to explore its impact. More recently, pharmacological profiling of disulfiram encourages its clinical evaluation as an anticancer agent [11].

\subsection{Disulfiram as a Proteasome Inhibitor}

Proteasome is an energy-dependent protease found in all three domains of life (Bacteria, Archaea, and Eucarya) and is a key regulator of many other cellular events including NF-kB signaling [12].

Proteasome is important for cell development and division, cell metabolism and DNA repair $[13,14]$. Proteasome controls the distribution, abundance, and activity of the transcriptional machinery and has a functional link to translation initiation with nonproteolytic roles in the cell, including those involved in nucleotide excision repair, recruitment of histone acetyltransferases to target promoters, transcription elongation and cell cycle control $[15,16]$.

Disulfiram and disulfiram derivatives; DDTC(diethyldithiocarbamate $; \mathrm{C}_{5} \mathrm{H}_{10} \mathrm{NS}_{2}$ ) and pyrrolidine dithiocarbamate (PDTC ; $\mathrm{C}_{5} \mathrm{H}_{9} \mathrm{NS}_{2}$ ), are well-known as $\mathrm{NF}-\kappa \mathrm{B}$ inhibitors which interfere with the NF- $\mathrm{B}$ pathway by inhibiting NF- $\kappa \mathrm{B}$ (Nuclear factor kappa binding) nuclear translocation [17,18], inhibition of I $\mathrm{B}$ phosphorylation [19] and proteasome degradation [18,19]. Disulfiram compound induces cancer cell apoptosis and exhibits proteasome inhibitory activity in some cancer cell lines $[19,18]$. Proposed mechanisms of action of Disulfiram include the induction of oxidative stress and inhibition of proteasome activity [20]. Proteasome inhibition in cancer cells leads to accumulation of pro-apoptotic target proteins and induction 
of cell death.

\subsection{Disulfiram as an Aldehyde Dehydrogenase Inhibitor}

The aldehyde dehydrogenases (ALDHs) have a broad spectrum of biological activities with ALDH activity being crucial to the biosynthesis of retinoic acid, an important regulator of vertebrate development, and to the metabolism of the neurotransmitter GABA [21-27].

Disulfiram (tetraethylthioperoxydicarbonic diamide), inhibits ALDH1A1 more potently than it does ALDH2 [28]

The molecular mechanism of ALDH inhibition is mediated by metabolic products of disulfiram. The first of these involves the reduction of the disulfide bond and concurrent liberation of diethyldithiocarbamate (DDTC), an inhibitor of ALDH in vivo but not in vitro [29-32]. DDTC is converted by hepatic thiol methyltransferase to $S$-methyl$N, N$-diethyldithiocarbamate (DETC; C6H13NS2) and $S$ methyl- $N, N$-diethyldithiocarbamate $\quad(\mathrm{Me}$ DDTC ;C6H13NOS2), both potent inhibitors of mitochondrial ALDH2 in vivo. Subsequent P450-catalyzed oxidation metabolites of DETC and Me-DDTC, including DETC-sulfoxide (DETC-SO) and $S$-methyl- $N, \quad N$ diethylthiocarbamate-sulfoxide (Me-DDTC-SO) and sulfone (Me-DDTC-SO $\mathrm{S}_{2}$ ), also inhibit mitochondrial ALDH [33-35]. The inhibition induced by all of these compounds is irreversible in nature because of carbamylation of the catalytic $\mathrm{HO}_{2} \mathrm{CCH}\left(\mathrm{NH}_{2}\right) \mathrm{CH}_{2} \mathrm{SH} \quad(\mathrm{Cys} 302)$ residue $[36,32,37]$.

\section{Copper Gluconate}

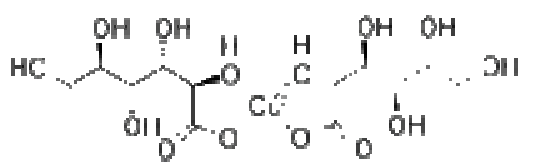

Fig 2. Chemical structure of Copper gluconate (http://www.newdruginfo.com/pharmacopeia/usp28/v28230/uspnf/pub/ima ges $/ v 28230 / g-212 . g i f)$

Copper gluconate is the copper salt of D-gluconic acid. An odourless, light blue or blue-green crystal or powder easily soluble in water and insoluble in ethanol [38]. Copper is a micronutrient found naturally in foods such as shellfish, beef, liver, whole grains, beans, peas, nuts, potatoes, green vegetables, and chocolate. Copper is needed to absorb iron from the gut and help regulate blood pressure and heart rate [39]. Copper is involved in numerous biochemical reactions in human cells. It is a component of multiple enzymes, and is involved with the regulation of gene expression, mitochondrial function/cellular metabolism, connective tissue formation, as well as the absorption, storage, and metabolism of iron. Scientists also know, based on many studies, that copper is a trace element needed to support nerve function and help the body use iron. It is important to a number of enzyme systems, and helps produce energy and skin colour (melanin). There are also claims, that copper helps healing, helps to expel toxins from the body, prevents thyroid problems, promotes healthy skin and hair, and helps prevent heart problems. Some claim that it can cure slipped discs, aneurysms, and even haemorrhoids [39].

Laboratory and animal studies have found that copper has antioxidant properties and may have some anticancer effects. Some studies have found that high copper levels in the blood were linked with cancer and other diseases. It's been advocated that more extensive human studies are needed to learn what role copper may play in preventing or treating cancer [39].

Copper is a trace mineral that is needed for many important body processes. Animal studies have shown that copper is useful in maintaining antioxidant defenses. Antioxidants block the actions of free radicals, which are activated oxygen molecules that can damage cells. While the role of copper in the cancer process is still unclear, copper complexes have been shown to have anticancer properties in laboratory studies [40].

Though a number of metal ions can enhance the antineoplastic activity of disulfiram, including $\mathrm{Zn}^{2+}$, it has been discovered that $\mathrm{Cu}^{2+}$ was the most active. An observation, which has been confirmed by other researchers, who have shown that $\mathrm{Cu}^{2+}$ supplementation of growth media increases the pro-apoptotic [7] and proteasomeinhibitory [10] activities of disulfiram [41-47] and have all documented that compared to surrounding normal tissue, many cancer cells contain highly elevated levels of copper.

\section{The Controversies}

Researchers have observed that in the presence of copper, disulfiram exhibits cytotoxic effects on a number of cancer cell lines. It is postulated that disulfiram, chemically a bis$\mathrm{N}$, N-diethyldithiocarbamate forms a carbamato complex with $\mathrm{Cu}^{2+}$ ions in situ which inhibits the proteasome activity, instigating apoptosis and eventual cell death [10]. However, some studies have found that high copper levels in the blood were linked with cancer and other diseases [39] and yet other researchers state that copper complexes have been shown to have anticancer properties in laboratory studies [40]. Copper is needed for angiogenesis, and because cancer needs new blood vessels in order to grow, some researchers are lowering copper levels to see if it will help slow tumour growth. In effect, the researchers are trying to use low copper levels to starve the tumour of nutrients by keeping it from building new blood vessels (antiangiogenesis ) [40]. Therefore the role of copper in cancer is as at yet not clear.

\section{Conclusion}

In the presence of $\mathrm{Cu}^{2+}$, disulfiram is converted to the two-electron oxidized form of diethyldithiocarbamate, which is the active form in inducing cell death [7]. Most of the literature reviewed, point to the efficacy of disulfiram on cancer cell lines and this is potentiated in the presence of copper ions. Therefore despite the controversies on the 
role of copper in cancer which only further research would clarify, the researchers conclude that there is a real probability that disulfiram when co-administered with a copper ion donor may prove to be a significant contribution to the armamentarium of cancer chemotherapy.

\section{References}

[1] Ferlay J, Shin HR, Bray F, Forman D, Mathers CD, Parkin D. GLOBO-CAN 2008, Cancer Incidence and Mortality Worldwide: IARC Cancer-Base No.10 [Internet]. Lyon, France: International Agency for Research on Cancer. 2010; Available from: http://globocan.iarc.fr.

[2] World Health Organization. World Cancer Report 2008. Lyon: Inter- national Agency for Research on Cancer;2008

[3] Chukwuma, M.(2006). Crude oil pollution raises cancer risk among Nigerians. African Cancer Centre

[4] Nwankwoala R,Georgewill O.A(2006) “ Analysis of the occurrence of cancerand other tumours in rivers and bayelsa states, Nigeria from December1997 to December 2000”. African Journal of applied zoology and Environmentalbiology,2006. Vol 8,48-53

[5] US Patent 1782111 - Method of Manufacturing Tetraalkylated Thiuramdisulphides

[6] Chen S.H, Liu S.H, Liang Y.C, Lin J.K, Lin-Shiau S.Y.(2001). Oxidative stress and c-Junamino-terminal kinase activation involved in apoptosis of primary astrocytes induced by disulfiram-Cu21 complex. Eur J Pharmacol. 414:177-188

[7] Cen D, Gonzalez R.I, Buckmeier J.A, Kahlon R.S, Tohidian N.B, Meyskens F.L Jr(2002). Disulfiram induces apoptosis in human melanoma cells: a redox-related process.Mol Cancer Ther. 1:197-204.

[8] Daniel KG, Chen D, Yan B, Dou QP (2008). Copper-binding compounds as proteasome Discov Today.13:716-722.

[9] Gupte A,Mumper J(2009) Elevated copper and oxidative stress in cancer cells as a target for cancer treatment. Cancer treatment reviews. Vol 35;32-46

[10] Chen D, Cui Q.C, Yang H, Dou Q.P(2006). Disulfiram, a clinically used anti-alcoholism drug and copper-binding agent, induces apoptotic cell death in breast cancer cultures and xenografts via inhibition of the proteasome activity. Cancer Res 66: 10425-33.

[11] Wickstrom M, Danielsson K, Rickardson L, Gullbo J, Nygren P, Isaksson A, et al.(2007). Pharmacological profiling of disulfiram using human tumor cell lines and human tumor cells from patients. Biochem Pharmacol 2007; 73: 25-33.

[12] Maupin-Furlow J.A, Humbard M.A, Kirkland P.A, Li W, Reuter C.J, Wright A.J, et al(2006). Proteasomes from structure to function: perspectives from archaea. Curr Top Dev Biol 75: 125-69

[13] Hershko, A(2005). The ubiquitin system for protein degradation and some of its roles in the control of the cell division cycle. Cell Death Differ 12: 1191-7
[14] Sutovsky P, Van Leyen K, McCauley T, Day B.N, Sutovsky M.(2004) Degradation of paternal mitochondria after fertilization: implications for heteroplasmy, assisted reproductive technologies and mtDNA inheritance. Reprod Biomed Online 8: 24-33

[15] Ferdous A, Gonzalez F, Sun L, Kodadek. T, Johnston $\mathrm{S} . \mathrm{A}(2001)$. The $19 \mathrm{~S}$ regulatory particle of the proteasome is required for efficient transcription elongation by RNA polymerase II. Mol Cell 7: 981-91.

[16] Gonzalez F, Delahodde A, Kodadek T, Johnston S.A.(2002). Recruitment of a $19 \mathrm{~S}$ proteasome subcomplex to an activated promoter. Science; 296: 548-50

[17] Lovborg H, Oberg F., Rickardson L, Gullbo J, Nygren P, Larsson R.(2006). Inhibition of proteasome activity, nuclear factor-KB translocation and cell survival by the antialcoholism drug disulfiram. Int. J Cancer.118:1577-1580.

[18] Matsuno T, Kariya R, Yano S, (2012). Diethyldithiocarbamate induces apoptosis in HHV-8infected primary effusion lymphoma cells via inhibition of the NF-kappaB pathway. Int J Oncol, 40, 1071-8.

[19] Cvek B, Dvorak Z (2007). Targeting of nuclear factorkappaB and proteasome by dithiocarbamate complexes with metals. Curr Pharm Des, 13, 3155-67

[20] Colin Rae (2013). The Role of Copper in DisulfiramInduced Toxicity And Radiosensitization of Cancer Cells. Journal of Nuclear Medicine, doi:10.2967/jnumed.112.113324

[21] Yoshida Y, Wang IC, Yoder HM, Davidson NO, Costa RH.(2007)" The forkhead box M1 transcription factor contributes to the development and growth of mouse colorectal cancer". Gastroenterology.132:1420-1431. doi: $10.1053 /$ j.gastro.2007.01.036

[22] Vasiliou V, Pappa A, Petersen DR(2000) Role of aldehyde dehydrogenases in endogenous and xenobiotic metabolism. Chem Biol Interact 129:1-19.

[23] Sophos NA, Vasiliou V(2003) Aldehyde dehydrogenase gene superfamily: the 2002 update. Chem Biol Interact 143144:5-22.

[24] Vasiliou V, Nebert DW(2005) Analysis and update of the human aldehyde dehydrogenase (ALDH) gene family. Hum Genomics 2:138-143

[25] Marchitti SA, Brocker C, Stagos D, Vasiliou V(2008) NonP450 aldehyde oxidizing enzymes: the aldehyde dehydrogenase superfamily. Expert Opin Drug Metab Toxicol 4:697-720.

[26] Niederreither K, Dollé $\mathrm{P}(2008)$ Retinoic acid in development: towards an integrated view. Nat Rev Genet 9:541-553.

[27] Kim KJ, Pearl PL, Jensen K, Snead OC, Malaspina P, Jakobs C, Gibson KM(2011a) Succinic semialdehyde dehydrogenase: biochemical-molecular-clinical disease mechanisms, redox regulation, and functional significance. Antioxid Redox Signal 15:691-718.

[28] Moore SA, Baker HM, Blythe TJ, Kitson KE, Kitson TM, Baker EN(1998) Sheep liver cytosolic aldehyde dehydrogenase: the structure reveals the basis for the retinal specificity of class 1 aldehyde dehydrogenases. Structure 6:1541-1551. 
[29] Deitrich RA, Erwin VG(1971) Mechanism of the inhibition of aldehyde dehydrogenase in vivo by disulfiram and diethyldithiocarbamate. Mol Pharmacol 7:301-307.

[30] Vallari RC, Pietruszko R(1982) Human aldehyde dehydrogenase: mechanism of inhibition of disulfiram. Science 216:637-639.

[31] Kitson TM(1983) Mechanism of inactivation of sheep liver cytoplasmic aldehyde dehydrogenase by disulfiram. Biochem J 213:551-554.

[32] Lipsky JJ, Shen ML, Naylor S(2001) In vivo inhibition of aldehyde dehydrogenase by disulfiram. Chem Biol Interact 130-132:93-102.

[33] Hart BW, Faiman MD(1995) Inhibition of rat liver low Km aldehyde dehydrogenase by thiocarbamate herbicides. Occupational implications. Biochem Pharmacol 49:157-163.

[34] Mays DC, Nelson AN, Lam-Holt J, Fauq AH, Lipsky JJ(1996) S-methyl-N,N-diethylthiocarbamate sulfoxide and S-methyl-N,N-diethylthiocarbamate sulfone, two candidates for the active metabolite of disulfiram. Alcohol Clin Exp Res 20:595-600.

[35] Mays DC, Ortiz-Bermudez P, Lam JP, Tong IH, Fauq AH, Lipsky JJ (1998) Inhibition of recombinant human mitochondrial aldehyde dehydrogenase by two intermediate metabolites of disulfiram. Biochem Pharmacol 55:10991103.

[36] Staub RE, Quistad GB, Casida JE(1999) S-methyl Nbutylthiocarbamate sulfoxide: selective carbamoylating agent for mouse mitochondrial aldehyde dehydrogenase. Biochem Pharmacol 58:1467-1473

[37] Shen ML, Johnson KL, Mays DC, Lipsky JJ, Naylor S.(2001) Determination of in vivo adducts of disulfiram with mitochondrial aldehyde dehydrogenase. Biochem Pharmacol 61:537-545.
[38] NRC (1980) Recommended dietary allowances. Food and Nutrition Board,National Research Council and National Academy of Sciences, Washington, D.C.

[39] Araya M, Olivares M, Pizarro F, Méndez Ma, González M, Uauy R(2005). Supplementing copper at the upper level of the adult dietary recommended intake induces detectable but transient changes in healthy adults. J Nutr. 135:2367-2371.

[40] Bügel S, Harper A, Rock E, O'Conner JM, Bonham MP, Strain JJ.(2005). Effect of copper supplementation on indices of copper status and certain CVD risk markers in young healthy women. Br J Nutr. 94:231-236.

[41] Habib FK, Dembinski TC, Stitch SR.(1980). The zinc and copper content of blood leucocytes and plasma from patients with benign and malignant prostates. Clin Chim Acta. 104:329-335. [PubMed

[42] Rizk SL, Sky-Peck HH (1984). Comparison between concentrations of trace elements in normal and neoplastic human breast tissue. Cancer Res. 44:5390-5394. [PubMed]

[43] Turecky L, Kalina P, Uhlikova E,(1984). Serum ceruloplasmin and copper levels in patients with primary brain tumors. Klin Wochenschr. 62:187-189. [PubMed

[44] Diez M, Arroyo M, Cerdan FJ,(1989). Serum and tissue trace metal levels in lung cancer. Oncology. 46:230-234. [PubMed]

[45] Huang YL, Sheu JY, Lin TH (1999). Association between oxidative stress and changes of trace elements in patients with breast cancer. Clin Biochem. 32:131-136. [PubMed]

[46] Kuo HW, Chen SF, Wu CC.(2002). Serum and tissue trace elements in patients with breast cancer in Taiwan. Biol Trace Elem Res. 89:1-11. [PubMed

[47] Nayak SB, Bhat VR, Upadhyay D,(2003). Copper and ceruloplasmin status in serum of prostate and colon cancer patients. Indian J Physiol Pharmacol. 47:108-110. [PubMed] 